\title{
O CEFETES COMO NÃO-LUGAR: LIMITES E POSSIBILIDADES NA INCLUSÃO DOS ALUNOS DO PROEJA-IFES/VITÓRIA
}

\author{
Maria da Glória Medici de Oliveira ${ }^{1}$, Eliesér Toretta Zen ${ }^{2}$
}

Pós-graduação Lato Sensu em Proeja, Instituto Federal do Espírito Santo Email: gloriamedici@uol.com.br, elieserzen@hotmail.com

\begin{abstract}
RESUMO
O presente artigo tem como finalidade provocar uma reflexão acerca do "não-lugar" do aluno Proeja no Instituto Federal do Espírito Santo - IFES, Vitória, das turmas de Metalurgia e Edificações e Materiais, referentes ao 50 módulo, a partir das discussões apresentadas por Marc Augé, assim como o princípio de "identidade" discutido por Heidegger. Buscando identificar e analisar posturas, sentimentos e relações presentes nas práticas pedagógicas dos professores - que expressam o "nãolugar" no cotidiano escolar - o trabalho apóia-se na obra de Freire, Pedagogia do Oprimido e Zimmermann, América Latina - o 'não ser', estabelecendo um diálogo na perspectiva de melhor compreender a constituição do espaço de pertencimento do aluno do Programa em Educação Profissional Técnica Integrada à Educação Básica na Modalidade de Educação de Jovens e Adultos Proeja. Pensando numa educação que contribui para a constituição da identidade desse aluno e pensando num "lugar" de pertencimento do mesmo buscamos respostas para solucionar as questões conflituosas apontadas ao longo do trabalho. Contextualizar a Instituição, desde seu surgimento até os dias atuais, levantar o perfil dos alunos que fizeram parte dessa história, pontuar as diversas fases que marcaram o IFES e, por fim, observar as inquietações do atual público do PROEJA, no seu espaço educativo, é o propósito deste trabalho monográfico. Para tanto fizemos uso dos seguintes instrumentos metodológicos: estudo de caso com grupo focal e entrevista/questionário, com a finalidade de identificar e analisar o perfil desse público.
\end{abstract}

Palavras-chave: IFES. Educação de Jovens Adultos. Não-lugar.

\section{INTRODUÇÃo}

Acreditando que a educação tem um papel importante a cumprir na constituição da identidade do sujeito de qualquer classe social, etnia ou cultura, enquanto professores do IFES ${ }^{3}$, campus Vitória, firmamos nosso compromisso em atender a todos os alunos de forma igualitária e lutar para que assim se cumpra a principal função da escola, que segundo Freire (1987) é educar para a prática libertadora. Sem perder de vista o conteúdo propedêutico, faz-se necessária a inclusão de práticas pedagógicas que possibilitem ao educando do Proeja, IFES-Vitória, encontrar seu "lugar" nessa instituição, já que constatamos as inúmeras dificuldades vivenciadas por eles quando da constituição de sua identidade com o espaço escolar.

\footnotetext{
${ }^{1}$ Licenciada em Filosofia pela Fundação de Ensino Superior de São João Del Rei - FUNREl; Especialista em Docência do Ensino Superior, FIJ, Rio de Janeiro; Especialista em Ensino Religioso pela UCB, Distrito Federal; Especialista em PROEJA, IFES, Vitória; Professora de Filosofia (PROEJA).

${ }^{2}$ Licenciado em Filosofia pela Pontifícia Universidade Católica de Minas Gerais, Especialista em Filosofia e Mestre em Educação pela Universidade Federal do Espírito Santo (UFES). Professor de Filosofia e Sociologia no Ensino Médio (PROEJA) e no Programa de Pósgraduação em Educação Profissional Integrada à Educação Básica na Modalidade de EJA do Instituto Federal do Espírito Santo Ifes Campus Vitória.

${ }^{3}$ Durante a realização da pesquisa, o Instituto Federal do Espírito Santo - IFES, era conhecido pelo nome de Centro Federal de Educação Tecnológica do Espírito Santo, ou seja, CEFETES.
} 
O presente artigo tem como objetivo refletir sobre o "lugar" de pertencimento desse sujeito, esperando minimizar as questões apontadas quanto aos conflitos presentes na Instituição desde o surgimento desse programa no IFES.

Esperamos apontar possibilidades para a conclusão do curso almejado, já que esses sujeitos têm muito a contribuir na formação social da comunidade à qual pertencem.

Inserimos no objetivo geral o fato de que o aluno Proeja ocupa seu "não-lugar" na instituição. Nessa perspectiva, a pesquisa pretende identificar posturas, sentimentos e relações presentes nas práticas pedagógicas dos professores, assim como verificar, não só o educando como sujeito dessa relação, mas também o educador como principal componente desse processo que, ao longo dos anos, tem garantido um importante papel na gerência do "não-lugar" e do "não-pertencimento" do grupo pesquisado.

A realização da pesquisa girou em torno da análise dos fatores subjetivos e objetivos que, nas suas contradições e complexidades, contribuem para a constituição do IFES como um "não-lugar" para os alunos do Proeja, das turmas de Metalurgia e Materiais e Edificações, especificamente das turmas do noturno, correspondentes ao 5o módulo, 2008/02. A escolha foi baseada na facilidade de comunicação com essas duas turmas e, também, nas variadas questões por elas oferecidas, no que diz respeito ao "lugar" de pertencimento desse grupo. Os constantes relatos das dificuldades apresentadas pelos mesmos, de assumirem seus lugares de direito e de fato, enchiam-nos de curiosidade e interesse pelo tema.

Recorrendo ao conceito de "não-lugar", buscamos nossas bases em Marc Auge (1994), antropólogo francês, que vem discutindo o tema a partir da supermodernidade. Refletir acerca do conceito mencionado, cuja questão permeia e limita a consciência de determinados alunos dessa instituição, impedindo ou cerceando sua liberdade na formação de uma identidade estabelecida a partir do "acontecimento apropriação", na linguagem de Heidegger (1987), torna-se primordial para definir a essência desse ser.

Entendemos que nossa contribuição provocará um amplo debate no que se refere às práticas pedagógicas, oportunizando uma reflexão sobre a questão da relação educador e educando.

\section{O CONCEITO DE “NÃO-LUGAR”}

A ideia inicial que vamos problematizar é aquela advinda dos conceitos europeus em que se estabelece a posição hegemônica da Europa em oposição ao resto do mundo. Também esse conceito permeia o imaginário coletivo, e ainda hoje encontramos a ideia do EU e do Outro em oposição a mim, sendo o EU sempre o referencial, nessa visão ocidentalizada (ZIMMERMANN, 1986). Herdar culturalmente esse conceito nos levou a tratar a questão do Outro, ou seja, aquele que não está em mim, como algo distante e complexo, com possibilidades de negação desse sujeito constituído no OUTRO.

Realizar uma investigação acerca do sujeito equivale saber que: "[...] toda representação do indivíduo é, necessariamente, uma representação do vínculo social que lhe é consubstancial." (AUGÉ, 1994, p.24). Daí a importância do "lugar" para esse sujeito e em que ele está se transformando a partir desse "lugar".

Heidegger (1987, p.14), em Carta sobre o Humanismo, aponta para a possibilidade do ser se realizar enquanto ser ontológico e nesse movimento:

[...] se pretendemos remediar a humanidade do homem, então teremos de previamente aprender duas coisas: a existir perante o inominado; a aceitar que o homem só será compreensível na proximidade do ser. Antes que o homem volte de si mesmo a dizer algo de inédito, terá novamente de inquirir acerca do ser [...] 
Tomando a citação acima, parece-nos ainda mais preocupante se considerarmos a segunda afirmação onde "o homem só será compreensível na proximidade do ser". O ser ontológico encontrase inserido no ser histórico, aliás, aquele é a expressão desse, ou seja, é nesse que o primeiro se faz, se autodetermina, se realiza, se constitui num devir constante. É na história que, determinado por espaço e tempo, o ser se produz.

Analisar um fato é considerar o espaço e o tempo a partir de uma perspectiva histórica, e nossa pesquisa tem delimitado um espaço de "não-lugar" do sujeito pesquisado, portanto um espaço que, diante das afirmativas apresentadas no decorrer desse trabalho, poderá contribuir para a problematização do ser.

Para enriquecer ainda mais nossa reflexão, Augé $(1994$, p.29) define a História como "uma série de acontecimentos reconhecidos como acontecimentos por muitos...", que, num certo sentido, caracterizam o mundo contemporâneo, quando se referem às histórias individuais referendadas pela história do coletivo. Desse modo, fica a ação individual vinculada ao grupo. Para que assim ocorra, outra variável se inclui: o mundo atual, caracterizado basicamente por espaços reduzidos com a nova organização sem fronteiras, de um mundo globalizado e interligado por "não-lugares". Para Augé (1994, p.36):

[...] não-lugares são tanto as instalações necessárias à circulação acelerada das pessoas e bens (vias expressas, trevos rodoviários, aeroportos) quanto os próprios meios de transportes ou os grandes centros comerciais, ou ainda os campos de trânsito prolongados onde são alojados os refugiados do planeta.

Para sua integração, a identidade individual encontra obstáculos com a identidade coletiva. Buscar um "lugar" comum, que exprima a identidade do grupo, passou a ser uma necessidade para o próprio reconhecer. De acordo com Augé (1994, p.45):

Não seria de se espantar que os termos desse discurso sejam geralmente espaciais, a partir do momento que o dispositivo espacial é, ao mesmo tempo, o que exprime a identidade do grupo (as origens do grupo são, muitas vezes, diversas, mas é a identidade do lugar que o funda, congrega e une) e o que o grupo deve defender contra as ameaças externas e internas para que a linguagem da identidade conserve sentido.

O contrário do "não-lugar" é então o "lugar" que identifica grupos, que se constitui por relações pessoais e interpessoais e, finalmente, que se faz histórico. É esse e desse "lugar" que direcionaremos nossa pesquisa, com a finalidade de resgatar o "lugar" que identificará o sujeito histórico do Proeja/IFES, na constituição de sua própria identidade e do grupo de pertencimento.

Em seu livro Que é isto - a Filosofia? Identidade e Diferença Heidegger (2006), concordando com Parmênides, entende que pensar e ser estão numa mesma relação de identidade, levando-nos a entender que: "pensar e ser têm seu lugar no mesmo e a partir deste mesmo formam uma unidade" (HEIDEGGER, 2006, p.41). Logo, a identidade que se delineia é aquela que se origina no ser, ou dela faz parte, incluindo aí o pensamento, que desse "lugar" comum também participa.

Ao analisarmos o ser na sua totalidade, ou simplesmente aquilo que é, deparamo-nos com o ser humano, sujeito, ente que se encontra na totalidade do ser, entregue ao outro como pertencimento. Pertence um ao outro e, portanto, também desfruta da mesma identidade de ser. É nessa constituição que a subjetividade se alimenta, forma-se ou transforma-se, faz-se ou desfaz-se na existência. 
Freire (1987) nos indica que, quando envolvidos por situações diversas, somos levados a comportamentos que refletem tais situações. De um lado, temos aqueles que sofrem a ação e, de outro, aqueles que a realizam. Tomando como modelo, e, portanto, observando nossos alunos do PROEJA, a questão que colocamos para reflexão desse trabalho é exatamente a construção desse sujeito, dessa subjetividade, permeado por ações que interferem na identidade do mesmo, cuja essência é partilhada e presente nesse espaço social.

\section{METODOLOGIA}

Essa pesquisa fundamenta-se em um Estudo de Caso o qual busca analisar e problematizar questões pertinentes a duas turmas do Proeja/IFES, Vitória, dos cursos de Metalurgia e Edificações, do 5으 módulo - 2008/02, conforme já aludido. A esses sujeitos pesquisados foi aplicado um questionário, visando traçar um perfil do aluno Proeja dessa unidade e para tanto foi constituído um grupo focal com o objetivo de escutar os sujeitos sobre o que pensam e sentem em relação ao tema em questão.

Como grupo focal entende-se o "conjunto de pessoas selecionadas e reunidas por pesquisadores para discutir e comentar um tema, objeto da pesquisa, a partir de sua experiência pessoal" (POWELL; SINGLE, 1996 apud GATTI, 2005). É bom esclarecer que essa metodologia foi aplicada com as duas turmas em questão. Após as primeiras explicações e apresentação da professora Cristina, cujo papel foi dar apoio à pesquisadora, o grupo recebeu uma questão abordando o tema principal, ou seja, a discussão se deu em torno do aluno e o seu lugar no CEFETES, atual IFES. Durante a discussão, nosso papel enquanto pesquisadores e professores de apoio foi somente de observadores, interferindo apenas diante de uma eventual necessidade. O grupo se colocou com tranquilidade diante da metodologia aplicada.

Pensar e definir um sujeito para pesquisa tanto quanto o objeto a ser pesquisado foi a principal atividade desenvolvida no trabalho, enquanto ainda projeto. Uma vez com essas definições, ficou claro que esse sujeito teria muito a contribuir, já que no decorrer dos semestres anteriores, os registros realizados em sala de aula indicavam uma demanda forte e significante no que diz respeito ao "não-lugar" do aluno do Proeja no IFES. São alunos que relatam importantes depoimentos que configuram o conflito do pertencimento e, consequentemente, refletem o "não-lugar".

Interessante ressaltar alguns dados observados tanto no questionário quanto nas discussões do grupo focal, como veremos a seguir, uma vez que através deles podemos construir uma sequência de raciocínio lógico que comprovará a demanda da temática aqui abordada.

A fim de estabelecer uma amostra bem precisa, optamos por delimitar nosso questionário apenas ao grupo específico retratado no trabalho, portanto desenvolvemos o mesmo somente para os alunos do Proeja/IFES, unidade Vitória, que cursavam o 5o módulo (2008/02) de Metalurgia e Materiais e Edificações, sendo selecionados aqueles que fizeram o ensino básico, nesta unidade, no período vespertino e, portanto, já frequentavam a Instituição há, pelo menos, 2 anos. Esse critério foi estabelecido devido à necessidade de se verificar, a partir de uma experiência, a hipótese levantada no projeto inicial, que diz respeito ao "não-lugar" do aluno Proeja na Instituição.

A entrevista foi aplicada antes da realização do grupo focal, pois segundo Gatti (2005), a discussão poderia vir a interferir nas respostas dos alunos. Porém, foi necessário atentar para o fato de que as questões propostas poderiam alterar futuros comentários no Grupo Focal, então procuramos realizála individualmente e com o mínimo de troca de informações possíveis.

Dentro do recorte especificado, fizeram parte da pesquisa um total de 14 (catorze) alunos que frequentaram o turno vespertino nos módulos anteriores. A pesquisa permitiu-nos constatar que $100 \%$ desses realizaram o Ensino Fundamental na rede municipal e estadual, logo oriundos do ensino público. Desses, $70 \%$ ficaram afastados da escola somente por um ano, enquanto que os demais, $29 \%$, permaneceram entre 02 a 05 anos afastados e somente 01 aluno confirmou estar afastado por mais de 10 anos, o que nos leva à conclusão de que o turno vespertino é um público com menor defasagem escolar. Esse dado é indicativo de que esse aluno tem um perfil que se aproxima do perfil 
do "aluno regular", ou melhor, aluno com possibilidades de completar os estudos no período regular, pelo menos no que diz respeito ao tempo escolar.

Gráfico 1: Tempo fora da escola

\section{TEMPO FORA DA ESCOLA}

MAIS DE 10 ANOS

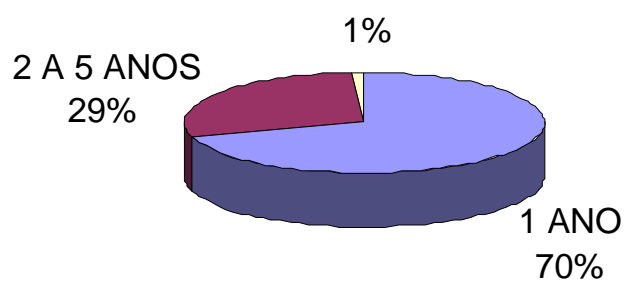

$\square 1$ ANO

$\square 2$ A 5 ANOS

$\square$ MAIS DE 10 ANOS

Um dado relevante, digno de nota, foi o motivo que os levou a permanecerem fora da escola. Dos $30 \%$ que estavam afastados há mais tempo, $90 \%$ não responderam, mesmo com as várias possibilidades oferecidas pelo questionário, e somente 01 assinalou "outras dificuldades", uma das alternativas dadas. Não se poderia apontar ser este já o primeiro indício de um possível constrangimento, quanto à sua condição, ou até mesmo, um fator contribuinte para a constituição do "não-lugar" desse sujeito?

No quesito sobre a situação de emprego, ficou comprovado que $50 \%$ são trabalhadores ativos e os outros $50 \%$ não, alguns por estarem desempregados no momento e outros por se encontrarem em situação confortável de não necessidade. Ainda desses trabalhadores, 70\% contribuem ativamente com a renda familiar, e os outros $30 \%$ não necessariamente. Importante foi certificar-se de que, aproximadamente, $80 \%$ têm casa própria e que desses, somente 01 aluno não mora com a família.

Seguindo os critérios étnico-raciais de cor, do IBGE, que inclui amarela, branca, preta, parda e indígena, $70 \%$ dos entrevistados consideram-se pardos, $10 \%$ pretos e $20 \%$ brancos (conforme quadro abaixo). Diante desses dados, concordamos com a teoria do embranqueamento ${ }^{1}$, em que persiste no Brasil um imaginário étnico-racial de valorização da brancura e das raízes européias refletidas nas informações acima. Poderíamos nos perguntar se não seria possível serem esses dados reveladores de um público que rejeita uma identidade que possa dificultar seu pertencimento ao Proeja/IFES.

Sobre a escolha da Instituição para realizarem o curso, chegamos a um resultado de que $70 \%$ deles procuraram o IFES como possibilidade de inserção no mercado de trabalho; $20 \%$ fizeram a escolha pela realização pessoal; e somente $10 \%$ optaram por essa instituição, motivados pela facilidade de conquistar uma vaga na Instituição por meio do Proeja.

\footnotetext{
${ }^{1}$ Embranqueamento: assumir os valores culturais do branco (ARAÚJO, 2006).
} 
Gráfico 2: Critério de cor

\section{CRITÉRIO DE COR}

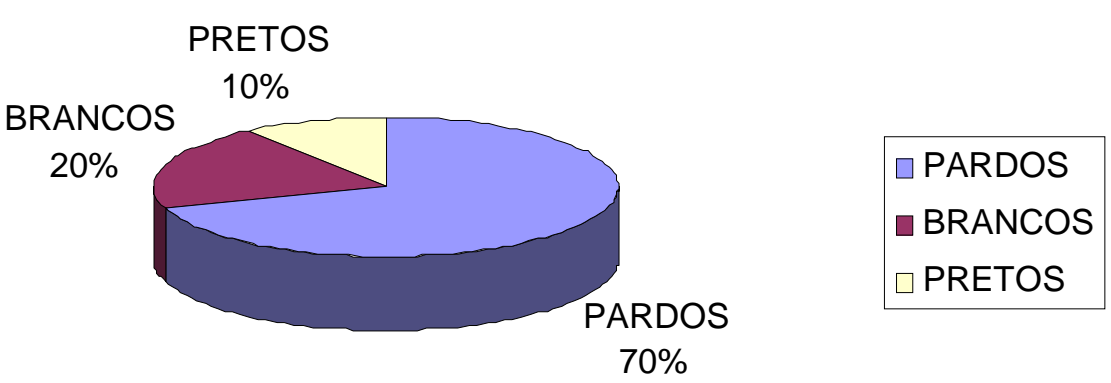

Ao serem indagados sobre as informações do curso que escolheram, $70 \%$ confirmaram que fizeram suas escolhas com conhecimento suficiente sobre seu curso, e apenas 30\% assumiram desconhecerem as informações necessárias. Mesmo assim, apenas um aluno declarou já ter pensado em abandonar o curso, por questões pessoais. No entanto, no último quesito, que abre possibilidade de algum depoimento, encontramos as seguintes declarações:

1) "Por muitas vezes temos que ajudar outros colegas para não desistirem. Portanto nos tornamos uma família."2

2) “Nunca, em hipótese alguma, cogitei em abandonar o curso, porque é uma vitória muito grande estar no CEFETES e ser aluna Proeja, só por isso é motivo mais que suficiente em continuar na luta." 3

Percebe-se que, no primeiro depoimento, o aluno deixa claro que o número de colegas que pensaram em abandonar o curso é significativo. No entanto, estatisticamente, isso não se efetiva. Já no depoimento seguinte, em contraposição ao primeiro, a aluna fala por si e, segundo ela, não cogita a hipótese de pensar em abandonar o curso. Numa análise mais criteriosa, podemos perceber, na primeira fala, indícios de quem precisa de apoio e sustentação, por exemplo, ao mencionar "...portanto nos tornamos uma família", ou ainda "...ajudar outros colegas para não desistirem". 0 discurso do "não-lugar" aparece subliminar nos trechos selecionados, pois a ideia de família é a própria ideia de proteção, com espaço bem demarcado e seguro.

$\mathrm{Na}$ última questão da entrevista/questionário, em que se pergunta se o aluno se reconhece como um aluno IFES-ES, foi interessante constatar que 100\% desses educandos possuem sentimento de pertencimento ao Instituto. Esse é um fato importante para esse artigo, uma vez que entendemos que o "lugar" para ser estabelecido necessita desse reconhecimento. Reportando a Heidegger (2006), pensar e ser têm seu lugar no mesmo e a partir deste mesmo formam uma unidade - um comum-pertencer. Pertencer significa estar integrado, inserido na ordem de uma comunidade. Os alunos pesquisados já iniciaram seu caminho para o estabelecimento do seu "lugar" no IFES. Poderia ser esse reconhecimento o passaporte, segundo Augé (1994), para a identidade desses sujeitos no espaço do "não-lugar". Assim, longe de se encontrarem sozinhos, estão ligados por algo em comum, por algo que possa realmente identificá-los.

\footnotetext{
${ }^{2}$ Aluno do PROEJA/CEFETES, 5o módulo do curso de Metalurgia e Materiais, turma N08.

${ }^{3}$ Aluna do PROEJA/CEFETES, 5o módulo do curso de Edificações, turma N05.
} 
$\mathrm{Na}$ segunda etapa da pesquisa, realizamos o grupo focal, utilizando as questões abaixo, que orientaram a conversa informal estabelecida a partir das mesmas. Apesar de um só propósito, sentimos necessidade de ampliar as possibilidades da conversa e, para tal, ao contrário de selecionarmos somente uma única questão, optamos por oferecer alternativas variadas de questões que conduzissem à temática, sendo elas:

Com quais questões vocês se depararam quando, desde o início, ingressaram no IFES/ Proeja e que tenham contribuído para dificultar a vivência de vocês aqui na Instituição? Vocês se sentiram como alunos dessa Instituição desde o início, quando aqui ingressaram? Este lugar - IFES - é um lugar que vocês reconhecem como seu? Vocês se sentem sujeitos que pertencem a esse lugar?

O sentimento inicial era de que tudo estava bem, e que aquele era o espaço ideal de aprendizagem. Foi assim percebido tanto no primeiro grupo (N05, turma 05 do técnico noturno) entrevistado, quanto no segundo grupo ( $\mathrm{N} \mathrm{08,} \mathrm{turma} 08$ do técnico noturno). Voltando a Heidegger (2006), tomando seu princípio de "acontecimento-apropriação", ou seja, a experiência, fica evidente a necessidade desses alunos de, já inicialmente, estabeleceram um lugar seguro e familiar para que se sentissem tranquilos, à vontade e até mesmo pertencentes àquele lugar. Sentir-se inserido na ordem de uma comunidade, segundo esse autor, é propiciar o desenvolvimento de uma identidade. Nesse sentido, o esforço desenvolvido pelos alunos para essa inserção, quando entram no IFES, é claramente perceptível.

A cumplicidade que se apresentou entre os alunos fortalece o sentimento de pertencimento de que precisam para seguirem adiante. Falar de "não-lugar" e estabelecer ideia a partir do imaginário coletivo, em princípio, é reconhecer a existência do Outro fora de mim. Nesse sentido, Zimmermann (1986), ao estudar o não-ser na América Latina, apresenta-nos o conceito de "eurocentrismo", que é tudo que existe fora de mim, isto é, fora daquilo que foi determinado como modelo ao qual EU pertenço é distante e complexo, portanto, passível de negação. Essa atitude está tão enraizada que facilmente é percebida, mesmo entre os indivíduos vitimados, o que podemos conferir, por exemplo, quando na entrevista da turma N 08, ao comentar sobre "aulas esquisitas":

K.: Primeiro o professor de história [... (risos)...] que manda apresentar um trabalho. Sobre outras religiões $[\ldots$ (risos)...] umbanda, candomblé $[\ldots$ (risos)...] tivemos que fazer uma pesquisa $[, \ldots]$ demorou um tempão para fazer a pesquisa, ai depois acho que pegou umas aulas dele para deixar a gente no laboratório de informática pesquisando, [...] ai depois a gente teve que apresentar 0 trabalho $[\ldots]$ estranho $[\ldots]$ esquisito $[\ldots]$

Moderadora: Vocês conseguiram?

K.: é conseguimos

Moderadora: Por que esse trabalho marcou?

K.: porque é esquisito, né? [...] falar de outras religiões [...]

Ar. : [...] que você não conhece.

K.: Conhecer a gente conhece você sabe [...]

Ar. : Não, nem sempre [...] a fundo, não, por exemplo, o que eu vejo sobre Islamismo eu nem imaginava tantas ramificações [...] o Islamismo é um [...] um conjunto de muitas religiões cada uma tem seu segmento [...]

Na. : Que é assim [...] O que tem haver com a história? A gente imaginava que a gente fizesse história, não religião.

K.: Ah [...] porque ele podia ter só comentado, mas ele levou o caso a fundo mesmo, a gente ficou um tempão pesquisando sobre esse assunto.

An. : Sobre história foi muito pouco [...] 
K.: Estranho [...] ai depois, ele acabou convidando a gente para visitar [...] visitar centro espírita, umbanda [...] lembra?

No trecho acima, percebe-se um estranhamento em relação às outras religiões, marcada principalmente pelos risos que encontramos entre, ou durante as falas. Interessante saber que, quando estamos no lugar com o qual nos identificamos, ficamos seguros e conscientes, mas, basta a inversão dos lugares para que não nos sintamos mais com o mesmo conforto, assumindo a identidade do próprio "não-lugar". E ainda, fazemos saber que, segundo Freire (1987), quando hospedamos a identidade do opressor, negamos nossa própria humanidade.

Encontramos no IFES alunos do Ensino Médio regular discriminando os que apresentam idade avançada, ou seja, presença, no mesmo espaço escolar, de diferentes gerações provocando conflitos. Identificamos essa atitude como a que tem maior eficácia quando se trata de estabelecer o "nãolugar". Mesmo porque, já acostumados a conviver num espaço socialmente seu, esse educando revela, nas mínimas atitudes, seu descontentamento com o sujeito Proeja, que na sua opinião, pouco fez para ingressar na Instituição. Daí um demérito se sobressai, o que dificulta ainda mais a constituição desse lugar.

Os professores também estão na lista daqueles que sustentam o IFES como "não-lugar" para os alunos do Proeja. Essa constatação foi verificada em depoimentos sobre a didática avaliativa, sendo aplicada como fator de exclusão. Como nos lembra Luckesi ${ }^{4}$ (apud NEVES, s.d., p. 02) a avaliação como castigo gera um sentimento de culpa, que provoca um engessamento no comportamento dos indivíduos, limitando e aqui entendemos criando o "não-lugar", ou excluindo esse sujeito. Para enfrentar e vencer esse momento, é necessária muita determinação por parte dos alunos.

A pesquisa monográfica que deu fundamento a esse artigo foi suficiente para constatarmos que, recorrendo a Heidegger, entendemos ser necessário o comprometimento de todos aqueles que gravitam em torno do sujeito Proeja/IFES, favorecendo o fazer desse ser histórico. Ao mesmo tempo, fundamentados na pedagogia freiriana, os dados comprovam que a necessidade de se construir um lugar comum a todos poderá vir da relação dialógica, que se expressa como uma necessidade a ser estabelecida no Proeja /IFES-Vitória. Aos responsáveis envolvidos com esse sujeito, cabe a árdua tarefa de descobrir movimentos dialógicos para interagirem e, assim, possibilitarem um lugar capaz de favorecer a constituição do ser.

\section{CONSIDERAÇÕES FINAIS}

A hipótese levantada no trabalho monográfico que deu origem a esse artigo considera o "não-lugar" dos alunos do Proeja no IFES, dos cursos de Edificações e Metalurgia e Materiais. O artigo pretendeu oferecer embasamentos e reflexões acerca de um problema que suscita muitas outras questões pertinentes a nossa pesquisa. Sem querer limitar e até mesmo encerrar a discussão, fica posto aqui que, longe de resolver o "não-lugar" do aluno Proeja no IFES-Vitória, vislumbramos muito mais que uma simples solução: uma mudança de atitude de toda uma comunidade educativa que, necessariamente, deve perceber-se como instrumento de manutenção ou de transformação do meio em que vive.

Durante todo o período que estivemos com nossas atenções voltadas para as questões pertinentes ao trabalho, pudemos verificar o quanto nossa problemática se contextualiza no espaço do IFES,

\footnotetext{
${ }^{4}$ Luckesi (1999) “A concepção da vida culpada, que atravessou épocas, não ocorreu por acaso. Esse processo se deu (e se dá) numa trama de relações sociais com a qual nos constituímos historicamente. O viés da culpa não é gratuito. A culpa gera uma limitação da vida e produz uma rigidez na conduta, o que, em última instância, produz um autocontrole sobre os sentimentos, os desejos e os modos de agir de cada um. Emerge, desta forma, um controle social internalizado, e cada um fica como se estivesse engessado, impossibilitado de expandir seus sentimentos e necessidades vitais. Interessa à sociedade em que vivemos esse engessamento dos indivíduos. A culpa impede a vida livre, a ousadia e o prazer, fatores, que multiplicados ao nível social, significam a impossibilidade de controle do processo de vida em sociedade, segundo parâmetros conservadores. A sociedade conservadora não suporta existir sem os mecanismos de controle internalizados pelos indivíduos - a culpa é, assim, muito útil”. Revista Iberoamericana de Educación (s.d., p. 53)
} 
demandando propostas necessárias e evidentes no que se referem ao "não-lugar" dos educandos nessa instituição. Transformar o "não-lugar" em "lugar" comum deve ser nosso objetivo principal, uma vez que as garantias legais não foram suficientes para assegurar o sentimento de pertencimento do público em questão.

A partir dessa perspectiva, o artigo buscou refletir sobre a inclusão desse novo público que, uma vez tendo garantido seu "lugar" no IFES de forma legal, também tenha condições de ocupar esse lugar enquanto direito subjetivo. Não obstante, buscou também contribuir para que esses sujeitos se reconheçam protagonistas de sua própria história, num "lugar" como direito de todo sujeito comum, resgatando uma identidade própria do ser, reconhecido enquanto tal.

\section{REFERÊNCIAS}

ARAÚJO, Ana Valéria (Org). Povos indígenas e a lei dos brancos: o direito à diferença. Brasília: MEC/SECAD; LACED/Museu Nacional, 2006.

AUGÉ, Marc. Não-lugares: introdução a uma antropologia da supermodernidade. São Paulo, Campinas, Papirus. 1994.

FERREIRA, E. B.; RAGGI, D. e RESENDE, M. J. A EJA integrada a educação profissional no CEFET: avanços e contradições. In: 30A. REUNIÃO ANUAL DA ANPED. Anais... Caxambu, MG: ANPED. Disponível em: http://www.anped.org.br/reunioes/30ra/trabalhos/GT09-3196--Int.pdf. Acesso em: 28 ago. 2009, 2007.

FREIRE, Paulo. Pedagogia do oprimido. Rio de Janeiro, Paz e Terra, 1987.

GATTI, Bernadete Angelina. Grupo focal na pesquisa em ciências sociais e humanas. Série Pesquisa em Educação, v.10. Brasília-DF, 2005.

HEIDEGGER, Martin. Que é isto - a filosofia? Identidade e diferença. Petrópolis, RJ. Vozes; São Paulo, Livraria Duas Cidades, 2006.

HEIDEGGER, Martin. Carta sobre o humanismo. Lisboa, Guimarães editores. 1987.

HENRIQUE, Antonio. O centro federal de educação tecnológica do espírito santo (Cefet-es) e o programa de integração da educação profissional à educação básica na modalidade de jovens e adultos (Proeja): um passo mais que presente. Revista Capixaba de Ciência e Tecnologia, Vitória, $\mathrm{n}$ 3, p. 44-49, 2. sem. 2007 - Edição especial-ensino profissionalizante.

LIMA, Marcelo. O desenvolvimento histórico do tempo socialmente necessário para a formação profissional: do modelo correcional-assistencialista das Escolas de Aprendizes Artífices ao modelo tecnológico-fragmentário do Cefet do Espírito Santo. 2004. 293 f., A4. Tese (Doutorado em Educação) - Universidade Federal Fluminense, 2004.

NEVES, Maria Augusta Ferreira. Revista Iberoamericana de Educación. S.d.

ZEN, Eliesér Toretta. Para além das teorias reprodutivistas da educação: uma abordagem sóciofilosófica. Revista Capixaba de Ciência e Tenologia. Vitória, n.2, p.44-49, 1. sem. 2007

ZIMMERMANN, Roque. América latina - o não ser: uma abordagem filosófica a partir de Enrique Dussel (1962-1976), São Paulo, 1986. 
